\title{
UTILIZAÇÃO DE PESTICIDAS NA PRODUÇÃO DE PÊSSEGOS 'MARLI', NOS SISTEMAS DE PRODUÇÃO INTEGRADA E CONVENCIONAL ${ }^{1}$
}

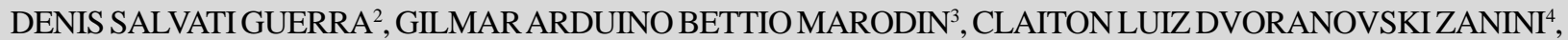 \\ FABIANO ARGENTA ${ }^{5}$, VINICIUS GRASELLI ${ }^{6}$, JOSÉ LUIS DA SILVANUNES $^{7}$
}

RESUMO -Diminuir o uso de defensivos e produtos de classes toxicológicas elevadas por outros mais seletivos e de menor impacto ambiental é uma necessidade na produção de pêssegos. Para tanto, os sistemas de Produção Integrada (PI) e Convencional (PC), em pessegueiros 'Marli', foram estudados durante a terceira safra na região da Depressão Central do Rio Grande do Sul. Há uma diminuição da aplicação de pesticidas na PI, principalmente de inseticidas, tanto no número de aplicações (34 \%) como na quantidade de ingrediente ativo (79 \%), e utilização de produtos mais seletivos aos artrópodos e menos nocivos ao homem e ao meio ambiente. Os danos nos frutos foram similares nos dois sistemas, com exceção da grafolita (Grapholita molesta), inseto que representa o principal problema fitossanitário do pessegueiro na região estudada.

Termos para indexação: Prunus, pragas, organofosforados

\section{PESTICIDES SPRAYS IN THE PRODUCTION SYSTEMS OF 'MARLI' PEACHES IN INTEGRATED AND CONVENTIONAL PRODUCTION}

\begin{abstract}
It is a necessity to peach production the reducing of pesticides and high toxicological class products by the use of products that causes less damage and are more selective. The Integrated (IP) and Conventional Production (CP) of 'Marli ' peach trees have been studied to reach this objective during the third year of conduction in the Central Depression of Rio Grande do Sul, Brazil. There is a decrease of the pesticides application in the IP, mainly insecticides, not only in the number of applications (34\%) as well as in the amount of active ingredient ( $79 \%$ ), and use of more selective products to arthropods which are less nocive to humans and environment. The damages on fruits were similar in the two systems, except for the Grapholita molesta, a pest wich represents the main phytosanitary problem of peaches in the area studied.
\end{abstract}

Index terms: Prunus, Pests, organophosphates,

\section{INTRODUÇÃO}

A falta de informações sobre medidas de segurança para a aplicação de pesticidas, bem como seus efeitos sobre o ambiente e a saúde humana predominam no meio rural. O impacto sobre o ambiente resulta na degradação lenta dos recursos naturais, em alguns casos irreversíveis, como a morte de animais silvestres, insetos úteis, peixes, contaminação da água e alimentos, com implicações diretas para a saúde humana (Gebara, 2002).

Os mercados mundiais, quando realizam suas importações, além da qualidade externa das frutas, passaram a exigir controle sobre todo o sistema de produção, incluindo a análise de resíduos nos frutos e os estudos sobre o impacto ambiental (Fachinello, 2000). O freqüente consumo de produtos com resíduos tóxicos pode resultar na exposição acumulativa, excedendo as doses máximas de referência (Dasgupta et al., 2002).

A Produção Integrada (PI) tem como objetivos reduzir o uso de agroquímicos de síntese, minimizar as perdas pré e póscolheita, utilizar práticas de manejo do solo que reduzam o impacto ambiental e o gasto de energia, oferecer à sociedade frutas de qualidade e manter a competitividade do produtor, com oferta de frutas certificadas e rastreadas (Fachinello et al., 2003).

Nunes et al. (2003) demonstram a diminuição da aplicação de defensivos na PI, comparada à Produção Convencional (PC), de fungicidas e, principalmente, de inseticidas, tanto no número de aplicações como no de ingrediente ativo, na mesma área de estudo deste experimento.

O objetivo deste trabalho é avaliar a possível diminuição do uso de defensivos e a substituição por produtos mais seletivos e de menor impacto ambiental nos sistemas de PI e PC.

\section{MATERIAL E MÉTODOS}

A área experimental localiza-se num pomar comercial de pessegueiros 'Marli'/Capdeboscq, com 11 anos de idade, no sistema de vaso aberto, com espaçamento de $6,0 \times$ 4,0 m, em duas parcelas, de um hectare, sendo avaliadas nos sistemas de Produção Convencional (PC) e Produção Integrada (PI), distanciados cerca de $500 \mathrm{~m}$ entre si, na região da Depressão Central do Rio Grande do Sul. Este trabalho é a avaliação dos resultados da terceira safra (2002), no mesmo local. Dados anteriores podem ser obtidos em Nunes et al. (2003).

\footnotetext{
${ }^{1}$ (Trabalho 212-2005). Recebido em 21-12-2005. Aceito para publicação em 04-12-2006.

${ }^{2}$ Eng. Agr. M. Sc., Rua General Lima e Silva 59/11, 90050-101, Porto Alegre, RS; d.s.guerra@ibest.com.br; CNPq

${ }^{3}$ Prof. Dr. da Fac. Agronomia/UFRGS, marodin@ufrgs.br; Av. Bento Gonçalves 7712, Porto Alegre, RS

${ }^{4}$ Eng.Agr.M. Sc./UFRGS claiton@terra.com.br; Av. Cavalhada 2167, 91740001, Porto Alegre, RS, Capes

${ }_{5}^{5}$ Eng. Agr. esporatravada@hotmail.com; Rua João Abott 302/ 201, 90460-150; Porto Alegre, RS; PIBIC/ CNPq

${ }^{6}$ Eng. Agr., vini@turbo.com.br; Av. Bento Gonçalves 7712, Porto Alegre, RS

${ }^{7}$ Eng. Agr. M. Sc./Doutornado UFRGS; jlsnunes@ hotmail.com; Av. Bento Gonçalves 7712, Porto Alegre, RS, CNPq
} 
A grafolita (Grapholita molesta) teve o monitoramento efetuado com armadilhas tipo Delta, com septo de borracha impregnado com feromônio sexual sintético, substituído após 45 dias. Em cada área experimental, foram utilizadas duas armadilhas. O Nível de Controle adotado para que fossem feitas pulverizações em cobertura, foi de 20 machos/armadilha/semana na PI, enquanto, na PC, as aplicações seguiram o calendário conforme a experiência do produtor (Tabela 1).

A mosca-das-frutas (Anastrepha fraterculus) foi monitorada com armadilhas plásticas tipo McPhail, contendo suco de uva $(25 \%)$ como atrativo alimentar. Na PI, o nível de controle para as pulverizações em cobertura total foi de 3,5 moscas/semana/armadilha e a aplicação de isca tóxica quando da presença de uma mosca/semana/armadilha. Na PC, o controle baseou-se no calendário utilizado pelo produtor, sem observar o nível populacional. O manejo das moléstias seguiu as Normas de Produção Integrada de Pêssego (PIP) de 2001, e os produtos utilizados encontram-se na Tabela 1.

A utilização de inseticidas e fungicidas foi avaliada através do número de aplicações, quantidade de ingrediente ativo aplicado por hectare (kg i.a./ha) e o custo da compra dos produtos (não foram avaliados os custos da aplicação, como tratorista, combustível e depreciação do trator). Para as aplicações, foi utilizado trator com turboatomizador $\left(1.000 \mathrm{~L}\right.$ de calda ha $\left.{ }^{-1}\right)$.

Os danos de insetos (grafolita e mosca-das-frutas) e doenças (podridão-parda - Monilinia fructicola, sarna Cladosporium carpophylum e bacteriose - Xanthomonas arboricola pv. Pruni), foram avaliados no momento das colheitas, através da avaliação visual e da contagem de frutos atacados pelo agente.

A análise dos dados foi feita através da utilização do software SAS 8.1, e a comparação entre os dois tratamentos (PI e PC), pelo Teste t, com 5\% de significância (podridão- parda, sarna, bacteriose, grafolita, mosca-das-frutas e total de danos).

\section{RESULTADOS E DISCUSSÕES}

Houve redução no número de aplicações de inseticidas em $34 \%$ e de ingrediente ativo por hectare, em $79 \%$ na PI, em relação à PC, na safra 2002. Os custos provenientes da compra dos produtos foram reduzidos na PI em $31 \%$, comparando-se com a PC (Figura 1). Desde a primeira safra, ocorreu progressivamente uma redução de i.a. aplicados em cada área. Essa diminuição confere com o observado nesta mesma área por Nunes (2003), obtido nas safras anteriores. Em outros países, como na Holanda, também é observada a diminuição de ingrediente ativo por hectare na PI (Heijne et al., 2001).

A PI teve maior número e porcentagem de frutos atacados por grafolita do que a PC (Figura 2). A redução de inseticidas ou a diferença do efeito entre os produtos utilizados em cada sistema pode ter ocasionado o aumento dos danos. Também houve aumento do percentual de frutos atacados, quando comparamos com as safras anteriores. Em 2001, a média foi de $4 \%$ e, em 2000 de $5 \%$ (Nunes, 2003). A PC e, principalmente, a PI apresentaram níveis de danos considerados muito altos.

A incidência de doenças teve o mesmo comportamento nos dois sistemas, evidenciando que a redução no número de aplicações de fungicidas em $27 \%$, de ingrediente ativo em $17 \%$ e do custo em $21 \%$, da PC para a PI, não aumentou as perdas por doenças na colheita (Figuras 1 e 2). Levando-se isso a um âmbito regional, a redução na utilização de defensivos pode trazer grandes benefícios econômicos (Brethour \& Weersink, 2001).

Mesmo tendo o mesmo número de aplicações, na PI, ou diminuição, na PC, houve aumento de ingrediente ativo de fungicidas nos sistemas, a cada nova safra, e isto está ligado à utilização de óxido cuproso no inverno de 2002 (Figura 1). A grande quantidade de umidade na floração e no início da frutificação também influenciou na maior aplicação de fungicidas no ciclo de 2002 .

TABELA 1 - Ingredientes ativos (i.a.), classe toxicológica, número de aplicações e quantidades utilizadass de fungicidas e inseticidas, com respectivos custos nos manejos PC e PI, na cv 'Marli', safra 2002. São Jerônimo-RS, 2004.

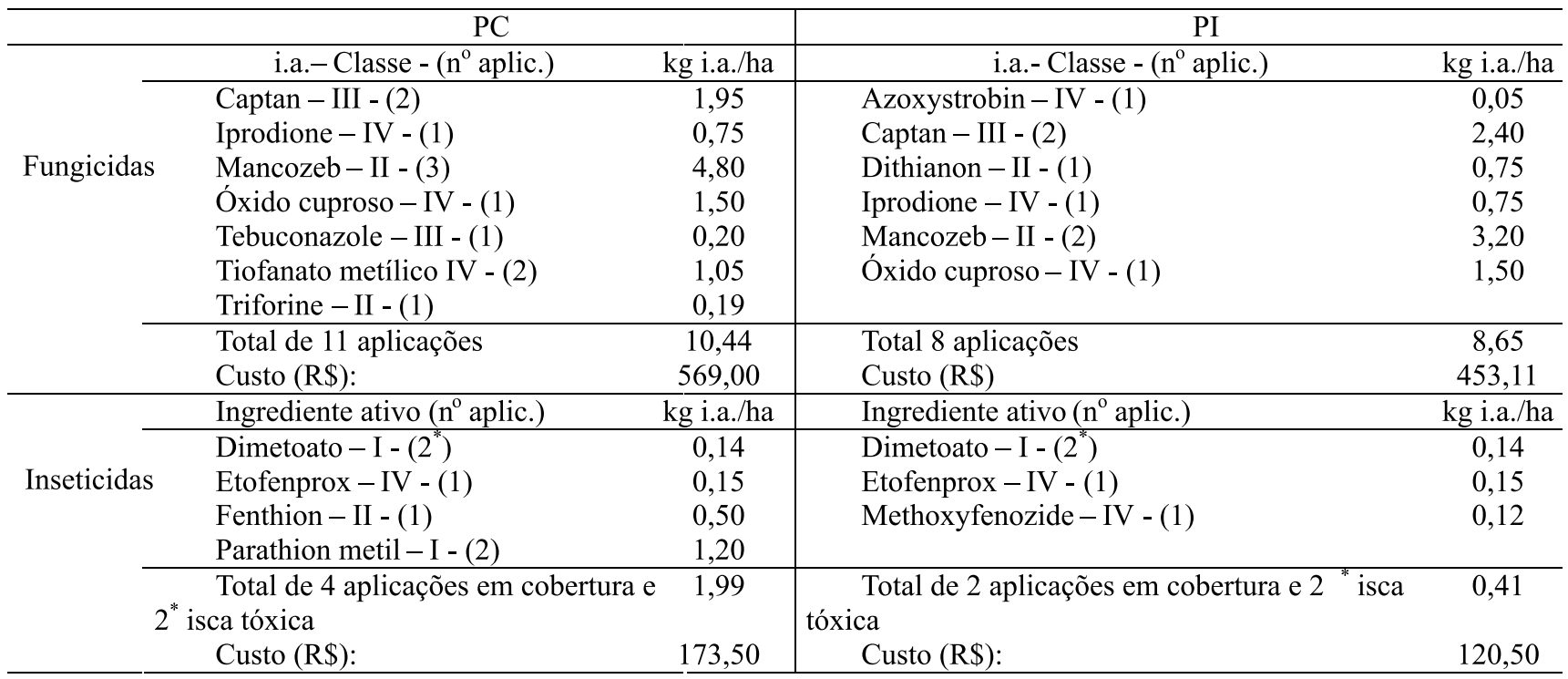

Rev. Bras. Frutic., Jaboticabal - SP, v. 29, n. 1, p. 091-095, Abril 2007 


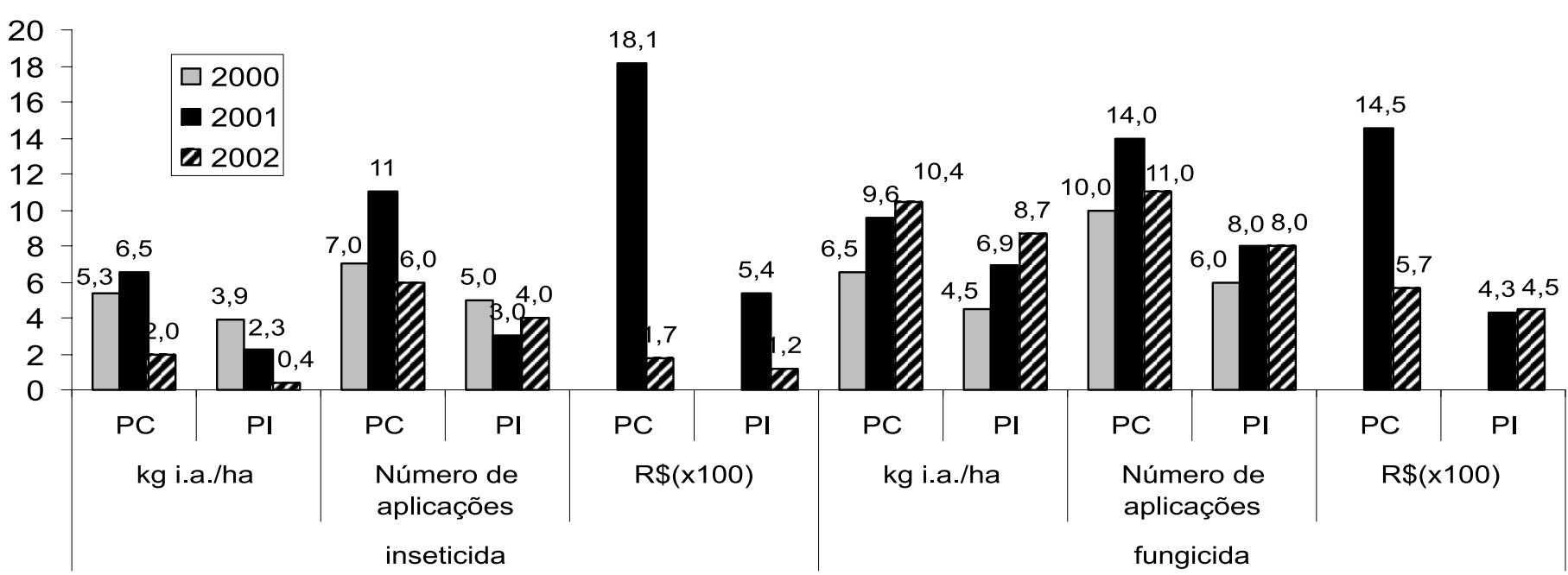

FIGURA 1 - Aplicações de inseticidas e fungicidas: quantidade de ingrediente ativo (kg i.a./ha), número de aplicações e custo dos produtos (R\$/ha), na cv. Marli, safras 2000, 2001 (Nunes, 2003) e 2002, nos sistemas de Produção Convencional (PC) e Integrada (PI), São Jerônimo - RS, 2004.

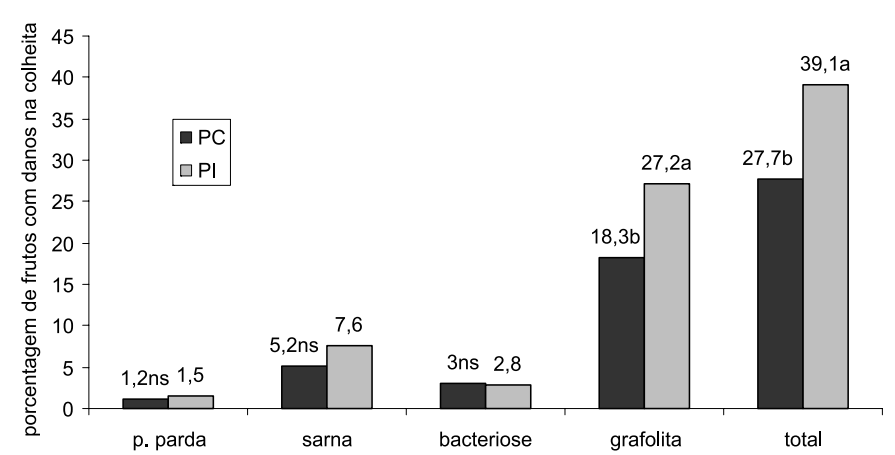

FIGURA 2 - Porcentagem de frutos com danos na colheita, safra de 2002, podridão- parda, sarna, bacteriose, grafolita e o total de perdas por pragas e moléstias nos sistemas de Produção Convencional (PC) e Integrada (PI), São Jerônimo - RS, 2004. Médias seguidas de letras distintas diferem pelo teste $\mathrm{t}$.

A decisão pela aplicação de defensivos na PC, segundo Pannell (1991), é o receio de prováveis perdas de produção. Não-necessariamente, o risco leva ao incremento na utilização pelos agricultores. Outros fatores, como a incidência de pragas e moléstias, e a efetividade no seu controle, podem levar à otimização do uso de pesticidas.

Os dados concordam com o que foi obtido por Botton et al. (2000), em que a PI teve índices maiores de perdas na colheita. A alta incidência de danos por grafolita na PI, neste trabalho, pode ser devida ao nível de alto controle adotado a esta cultivar.

A aplicação dos produtos na PI, para o controle da grafolita, não pode seguir a metodologia proposta nas normas de PI, cujo nível de controle é de 20 machos por semana. O

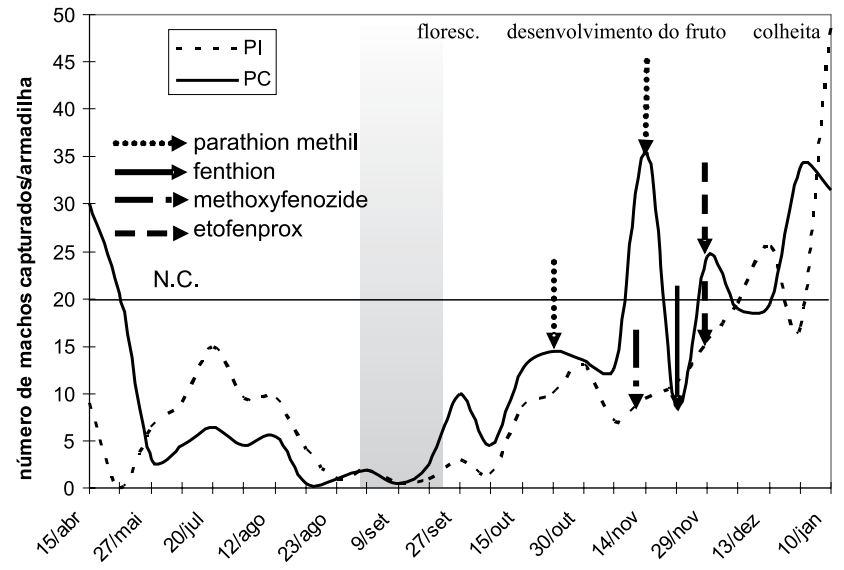

FIGURA 3 - Monitoramento de Grapholita molesta com inseticidas aplicados em pessegueiros 'Marli', nos sistemas de Produção Integrada (PI) e Convencional (PC), durante a safra de 2002, avaliado pelo número de machos capturados em armadilhas tipo Delta com feromônio sexual. São Jerônimo - RS.

monitoramento através de armadilhas apresenta dificuldades no estabelecimento do nível de controle, devido ao inseto apresentar várias gerações durante o ciclo. Assim, o dano pode ser acumulado ao longo das gerações, o que já havia sido relatado por Botton et al. (2000). Observou-se, durante o desenvolvimento dos frutos, um grande ataque da praga, o que motivou a aplicação de methoxyfenozide, mesmo não atingindo o limite do nível de controle. Dessa forma, deve ocorrer uma mudança na metodologia para o uso desse produto. Faz-se necessário testar outros modelos de armadilha, como, por exemplo, a Wing Trap, pois, segundo Arioli (2003), essa é mais eficiente na captura de machos da grafolita quando comparada à Delta.

Segundo Afonso (2001), os melhores resultados no 
controle de grafolita pelo methoxyfenozide em pomar de pessegueiro são obtidos com concentrações entre 144 e 288 gramas/ha/aplicação, acima da utilizada neste experimento, que foi de 120 gramas/ha. Essa dose foi utilizada com base no trabalho realizado por Nunes (2003), com a cv. Coral 2, no mesmo pomar, quando o methoxyfenozide diminuiu os danos por grafolita, nos frutos, em $83 \%$, comparado com o parathion methil. O monitoramento com o nível de dano econômico em 30 machos/ armadilha/semana e a utilização do produto foram satisfatórios. Ao contrário, a concentração utilizada na cultivar Marli mostrouse ineficiente, comparando com a cv. Coral 2. Esse resultado pode estar associado, também, à preferência diferenciada da praga por algumas cultivares, o que já havia sido verificado por Afonso (2001).

O monitoramento demonstrou que a utilização do etofenprox não alterou o número de mariposas capturadas (Figura 3 ). Isto pode ter ocorrido devido à menor concentração de ingrediente utilizada - $0,15 \mathrm{~kg}$ de i.a./ha/aplicação. No Japão, utiliza-se a concentração de $0,20 \mathrm{~kg}$ de i.a./ha e, no máximo, de $0,80 \mathrm{~kg}$ de i.a/ha por ciclo no pessegueiro (FAO, 2003).

O ponto-chave do controle da grafolita, na PI, é encontrar o nível de controle, na cv. Marli, com a utilização de armadilhas Delta, após atingido este nível, com a dose necessária de etofenprox ou methoxyfenozide ao controle eficiente dessa praga.

$\mathrm{Na} \mathrm{PC}$, apesar de menor, a incidência de grafolita também foi alta e, para o controle ser mais efetivo, o número de aplicações deveria ser maior e/ou mudanças dos produtos químicos deveriam ocorrer. O monitoramento indicou pouca incidência de grafolita, conforme coleta nas armadilhas, mas houve alta incidência nos frutos.

O controle da mosca-das-frutas, apenas com a utilização de iscas tóxicas com dimetoato, foi eficiente na safra de 2002, onde não houve diferença entre os sistemas, e os danos foram próximos a zero (dados não-apresentados). Isto leva a crer que o monitoramento e os produtos utilizados na PI são eficientes no controle dessa praga. Além da menor aplicação de defensivos, utiliza-se um gama de produtos menos tóxicos ao ambiente e à saúde humana. A aplicação de defensivos específicos para a mosca deve ocorrer quando as frutas estão no estádio de inchamento, normalmente 20 a 25 dias antes da colheita (Salles \& Kovaleski, 1990). Conseqüentemente, a composição de cultivares no pomar tem influência na época de início da incidência de moscas, na manutenção e aumento das populações que se seguem.

Os percentuais totais de frutos danificados por insetos e moléstias, e o seu somatório são apresentados na Figura 2. Na safra de 2002, não houve diferença na incidência da podridãoparda, sarna e bacteriose entre os dois sistemas, resultados semelhantes aos obtidos por outros autores em 'Chiripá' (Botton et al., 2000) e 'Eldorado' (Coutinho et al., 2003).

Na safra de 2002, na PI, 39,1\% dos frutos foram descartados, contra $27 \%$ na PC. O forte ataque de grafolita foi responsável pelo percentual de frutos descartados ter sido superior na área de PI. Esses resultados contrariam os obtidos por Coutinho et al. (2003) com a cv. Eldorado, na Serra do Sudeste do Rio Grande do Sul, em que o percentual de frutos descartados entre os dois manejos não chegou a $20 \%$, e, ao contrário deste experimento, o grande problema fitossanitário foi a incidência de mosca-das-frutas.

Apesar das maiores perdas de frutos na PI, comparada à PC, o manejo das plantas neste sistema resultou em maior produção de frutos na colheita $(11,8$ e $5,5 \mathrm{~kg} /$ planta, respectivamente), demonstrando que é economicamente viável ao produtor e ecologicamente mais correto.

\section{CONCLUSÕES}

A Produção Integrada permite reduzir a aplicação de inseticidas em $79 \%$ de i.a. e $17 \%$ de i.a. em fungicidas. Os danos nos frutos, causados por podridão-parda, sarna, bacteriose e mosca-das-frutas, são iguais nos dois sistemas. Os danos causados por grafolita são maiores na PI. O nível de controle em 20 machos/armadilha/semana e os inseticidas utilizados não reduziram esses danos.

\section{REFERÊNCIAS}

AFONSO, A.P.S. Controle da Grapholita molesta (Busck, 1916) (Lepidoptera: Tortricidae) no sistema de produção integrada de pêssegos. 2001. 62f. Dissertação (Mestrado em Fitossanidade), Faculdade de Agronomia Eliseu Maciel, Universidade Federal de Pelotas, Pelotas, 2001.

ARIOLI, C.J. et al. Bioecologia e controle da Grapholita molesta (Busck, 1916) (Lepidoptera: Tortricidae) em fruteiras temperadas. In: ENCONTRO NACIONAL SOBRE FRUTICULTURA DE CLIMA TEMPERADO, 6., 2003, Fraiburgo. Anais... Caçador-SC: Epagri, 2003. p. 110- 115.

BOTTON, M. et al. Avaliação do sistema de Produção Integrada de Pêssego de mesa na Serra do RS - Safra 1999-2000. In: SEMINÁRIO SOBRE PRODUÇÃO INTEGRADA DE FRUTAS DE CLIMA TEMPERADO NO BRASIL, 2., 2000, Bento Gonçalves. Anais... Bento Gonçalves: EMBRAPA Uva e Vinho, 2000. p. 64-77.

BRETHOUR, C.; WEERSINK, A. An economic evaluation of the environmental benefits from pesticide reduction. Agricultural Economics, Kent, v. 25, p. 219-226, 2001.

COUTINHO, E.F. et al.. Comparação entre os sistemas de produção integrada e convencional de pêssegos cv. eldorado, na região da Serra do Sudeste do Rio Grande do Sul. In: SEMINÁRIO SOBRE PRODUÇÃO INTEGRADA DE FRUTAS DE CLIMA TEMPERADO NO BRASIL, 5., 2003, Bento Gonçalves. Resumos... Bento Gonçalves: EMBRAPA Uva e Vinho, 2003. p. 84.

DASGUPTA, S. et al. Y. Agricultural trade, development and toxid risk. World Development, Montreal, v. 30, n. 8, p. 1401-1412, 2002.

FACHINELLO, J. C. Proposta de Projeto para Produção Integrada de Frutas de Caroço. In: SEMINÁRIO SOBRE PRODUÇÃO INTEGRADA DE FRUTAS DE CLIMA TEMPERADO NO BRASIL, 1999, Bento Gonçalves. Anais... Bento Gonçalves: EMBRAPA Uva e Vinho, 2000. p. 10-23. 
FACHINELLO, J.C. et al.. Rastreabilidade para frutas frescas e para conservas. In: ENCONTRO NACIONAL SOBRE FRUTICULTURA DE CLIMA TEMPERADO, 6., 2003, Fraiburgo. Anais... Caçador-SC: Epagri, 2003. p. 65-72.

FAO. Disponível em: www.fao.org/pesidid/etofenprox.pdf. Acesso em: 10 de agosto de 2003.

GEBARA, A.B. Resíduos de Pesticidas em Frutas. In: ENCONTRO NACIONAL SOBRE FRUTICULTURA DE CLIMA TEMPERADO, 5., 2002, Fraiburgo. Anais... Caçador-SC: Epagri, 2002.p. 31-33.

HEIJNE, B.; et al.. Economic Analysis of Integrated Fruit Production (IFP) Systems of apple in the Netherlands. In: SEMINÁRIO SOBRE PRODUÇÃO INTEGRADA DE FRUTAS DE CLIMA TEMPERADO NO BRASIL, 3., 2001, Bento Gonçalves. Anais... Bento Gonçalves: EMBRAPA Uva e Vinho, 2001.p. 1-8.

NORMAS de Produção Integrada de Pêssego (PIP): versão II/ ed. Bagé: URCAMP; Pelotas: UFPel: Embrapa; Porto Alegre: UFRGS, 2001.52p.

NUNES, J.L.da S. Estudo comparativo de sistemas de produção integrada e convencional de pessegueiro. 2003. 122f. Dissertação (Mestrado em Fitotecnia), Faculdade de Agronomia, Universidade Federal do Rio Grande do Sul, Porto Alegre, 2003.

PANNELL, D.J. Pests and pesticides, risk and risk aversion. Agricultural Economics, Kent, v. 5, p.361-383, 1991.

SALLES, L.A; KOVALESKI, A. Mosca-das-frutas em macieira e pessegueiro no Rio Grande do Sul. Horti Sul, Pelotas, v. 1, n. 3, p 5-9, 1990. 